\title{
Effects of Tungsten and Boron Contents on Crystallization Temperature and Microhardness of Tungsten Based Metallic Glasses
}

\author{
Pelin Öztürk • Aytekin Hitit
}

Received: 15 August 2014/Revised: 13 November 2014/Published online: 21 March 2015

(C) The Chinese Society for Metals and Springer-Verlag Berlin Heidelberg 2015

\begin{abstract}
Effects of tungsten and boron contents on the thermal properties and microhardness of W-Fe-B metallic glass system were studied. Thin foils, with thicknesses of 20 and $100 \mu \mathrm{m}$, of the alloys were produced by piston and anvil method in an arc furnace. The structures of the foils were investigated by X-ray diffraction. Thermal stabilities of the alloys were examined by using differential scanning calorimetry. $20-\mu \mathrm{m}$ - thick foils of all the alloys were determined to be fully amorphous, but crystalline phases were detected in the 100- $\mu \mathrm{m}$-thick foils. It was found that crystallization temperatures of the alloys are between 1060 and $1177 \mathrm{~K}$. Tungsten and boron content increases improve the crystallization temperature and microhardness of the alloys significantly, but deteriorate the glass forming ability of the alloys. It was also observed that for constant Fe content, increasing tungsten content to the level higher than that of boron content does not result in any further improvement in crystallization temperature, but improves glass forming ability significantly. The alloy containing highest total amount of tungsten and boron, $\mathrm{W}_{35} \mathrm{Fe}_{35} \mathrm{~B}_{30}$, has the highest crystallization temperature, $1177 \mathrm{~K}$, and microhardness, $1634 \mathrm{HV}$.
\end{abstract}

KEY WORDS: Metallic glass; Refractory metal; Crystallization temperature; Hardness

\section{Introduction}

Multicomponent bulk metallic glasses (BMGs) have received great attention because of their excellent physical, chemical and mechanical properties [1]. The major factor limiting the usage of a bulk metallic glass at high temperatures is its crystallization temperature, above which it crystallizes and loses its excellent properties. Therefore, crystallization temperature of a metallic glass alloy should be as high as possible in order to use it at higher temperatures. In general, crystallization temperature of a metallic glass is higher, if it contains elements having high melting points. In fact, $\mathrm{Ta}-[2,3], \mathrm{Nb}-$

Available online at http://link.springer.com/journal/40195

P. Öztürk · A. Hitit $(\bowtie)$

Department of Materials Science and Engineering, Afyon

Kocatepe University, 03200 Afyonkarahisar, Turkey

e-mail: hitit@aku.edu.tr
[2, 4, 5], Mo- [6, 7], Re- [8] and W-based [9-13] metallic glasses have been developed. In one of these refractory-based metallic glasses, a crystallization temperature as high as $1456 \mathrm{~K}$ has been reported [2]. Also, in these alloys, microhardness values of $2447 \mathrm{HV}$ [12] and $2400 \mathrm{HV}$ [13] have been obtained. However, the costs of the components, such as ruthenium, rhenium, iridium, tantalum and niobium, used in these alloys are so high that the usage of these alloys is believed to be quite limited. Among the refractory metal-based metallic glass systems, W-Fe-B alloys seem to be the most cost-effective. Indeed, these alloys can even be more costeffective by producing those using industrial raw materials ferroboron and ferrotungsten. In a previous study [11], it has been shown that $\mathrm{W}-\mathrm{Fe}-\mathrm{B}$ metallic glasses can have quite high crystallization temperature of $1067 \mathrm{~K}$. Therefore, it is believed that $\mathrm{W}-\mathrm{Fe}-\mathrm{B}$ metallic glasses deserve further investigation to determine whether they can have thermal and mechanical properties comparable with other refractorybased metallic glasses. 
At this point, it must be mentioned that the major problem of all the refractory metal-based metallic glasses is that they have very low glass forming ability (GFA) because of their extremely high liquidus temperatures. In fact, in most of the studies on refractory metal-based metallic glasses, liquidus temperatures of amorphous alloys have not been reported. Such a low GFA values result in very low casting thicknesses, which are in the order of 20-50 $\mu \mathrm{m}$, and limit their utilization for industrial applications. Therefore, when focusing on the improvement in thermal stabilities and mechanical properties of these alloys, one must also consider improving their GFA values in order to produce them with higher casting thicknesses. Obviously, finding alloy compositions having optimum thermal and mechanical properties and GFA only can be possible through systematic investigations. We believe that the first step of these investigations should be determining the alloy compositions that have high thermal stability and improved mechanical properties. Then, increasing the GFA of alloys can be considered.

In this paper, we report our study on effects of tungsten and boron contents on crystallization temperature and microhardness of $\mathrm{W}-\mathrm{Fe}-\mathrm{B}$ metallic glasses.

\section{Experimental}

\subsection{Alloy Design}

It is known that in an alloy system, an alloy having composition of deep eutectic has a high GFA because it has a high reduced glass transition temperature $T_{\mathrm{g}} / T_{\mathrm{L}}$. Unfortunately, for $\mathrm{W}-\mathrm{Fe}-\mathrm{B}$ alloy system, there is no available information about its liquidus projection. For this reason, it is not possible to choose a eutectic composition as a starting point in this system for our study. Therefore, three series of $\mathrm{W}-\mathrm{Fe}-\mathrm{B}$ alloys were produced. In the series 1 , tungsten content is always lower than boron content. In the series 2, tungsten and boron contents are always equal to each other. Finally, for the series 3, tungsten contents are kept higher than boron contents. For all series, iron contents are systematically decreased and tungsten and boron contents are systematically increased. As a result, W-Fe-B alloys with compositions of $\mathrm{W}_{25} \mathrm{Fe}_{45} \mathrm{~B}_{30}, \mathrm{~W}_{27.5} \mathrm{Fe}_{40} \mathrm{~B}_{32.5}$, $\mathrm{W}_{27.5} \mathrm{Fe}_{45} \mathrm{~B}_{27.5}, \mathrm{~W}_{30} \mathrm{Fe}_{40} \mathrm{~B}_{30}, \mathrm{~W}_{30} \mathrm{Fe}_{45} \mathrm{~B}_{25}, \mathrm{~W}_{32.5} \mathrm{Fe}_{40} \mathrm{~B}_{27.5}$ and $\mathrm{W}_{35} \mathrm{Fe}_{35} \mathrm{~B}_{30}$ were prepared.

\subsection{Sample Preparation and Characterization}

Master alloys were prepared by arc-melting the mixtures of 99.9\% pure $\mathrm{W}, 99.9 \%$ pure Fe and $98 \%$ pure crystalline B in a Ti-gettered high-purity argon atmosphere. In order to ensure homogeneity, samples were melted three times.
Compositions of the alloys represent the nominal atomic percentages. Thin foils of the alloys were produced by piston and anvil method in an arc furnace. For the production of the thin foils, a molten sample of each alloy was squeezed between two copper plates pushed by pneumatic pistons, as shown in Fig. 1. Velocity of each piston was about $400 \mathrm{~mm} / \mathrm{s}$. Thicknesses of the foils were determined by optical microscopy and were found to be about $20 \mu \mathrm{m}$. In addition, $100-\mu$ m-thick samples of the alloys were produced by piston and anvil method with the piston velocity of $50 \mathrm{~mm} / \mathrm{s}$. The as-cast structures of the foils were examined by X-ray diffraction (XRD, Shimadzu XRD-6000) with $\mathrm{Cu} K_{\alpha}$ radiation. The glass transition temperature $\left(T_{\mathrm{g}}\right)$, crystallization temperature $\left(T_{\mathrm{x}}\right)$, melting temperature $\left(T_{\mathrm{m}}\right)$ and liquidus temperature $\left(T_{\mathrm{L}}\right)$ of the alloys were measured by differential scanning calorimetry (DSC, Netzsch STA $449 \mathrm{~F} 3$ ) at a heating rate of $0.33 \mathrm{~K} / \mathrm{s}$ under a flowing highpurity argon. Vickers hardness of the samples was measured with a Vickers hardness tester (Shimadzu HMV 2L) under a load of $0.98 \mathrm{~N}$ with a dwell time of $15 \mathrm{~s}$. For each alloy, ten hardness measurements were taken randomly and arithmetic average of these measurements was taken as the microhardness of the alloy.

\section{Results}

XRD patterns of the 20 - $\mu$ m-thick samples of the alloys are given in Fig. 2. In the XRD patterns, broad diffraction peaks, which are typical of amorphous structure, at around $2 \theta$ of $43^{\circ}$ and $75^{\circ}$ are observed. None of the samples show sharp crystalline peaks, which indicates that samples have amorphous structure. However, XRD patterns of the $100-\mu \mathrm{m}$-thick samples of the alloys contain crystalline

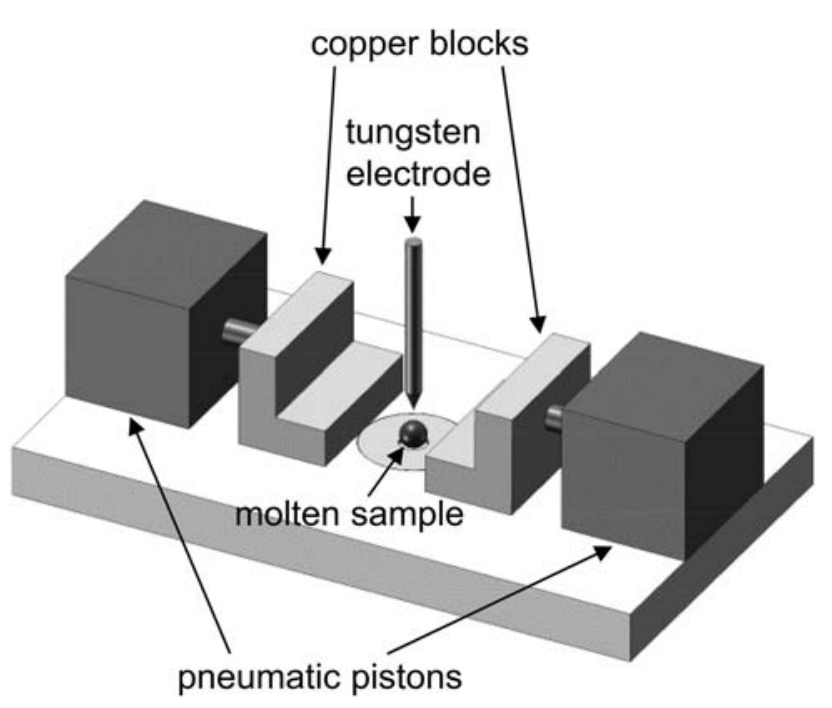

Fig. 1 Schematic diagram of piston and anvil apparatus 


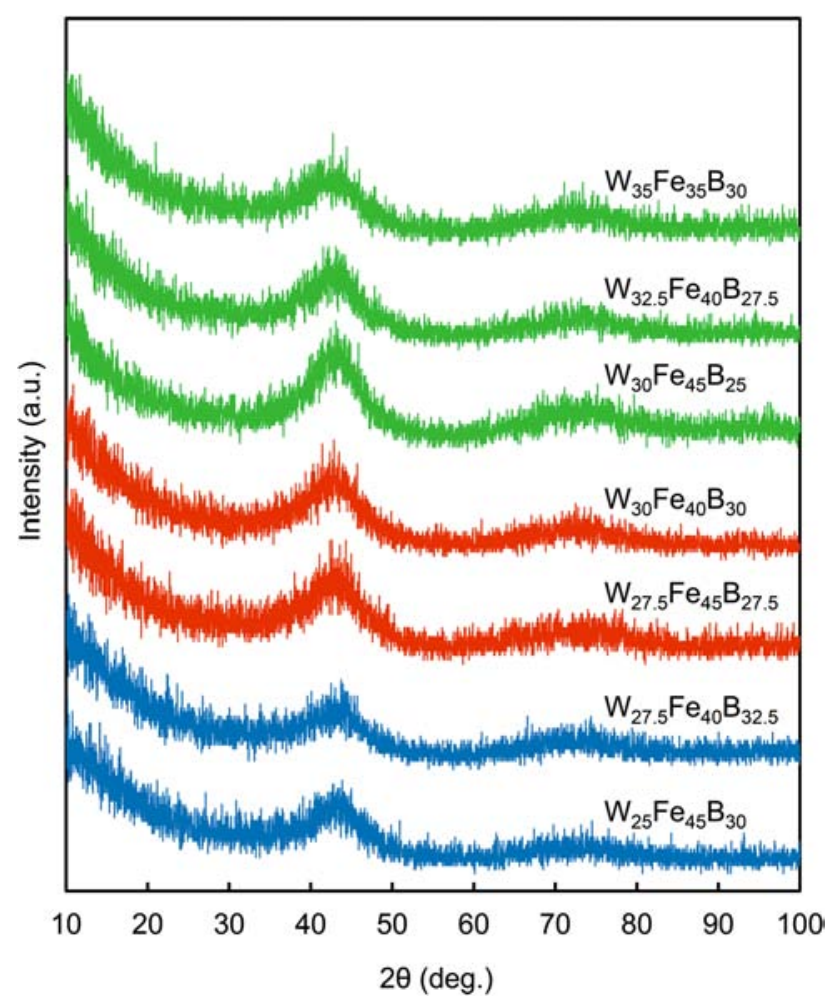

Fig. 2 XRD patterns of the $20-\mu \mathrm{m}$-thick samples of the alloys

peaks, which indicate that critical casting thicknesses of the alloys are $<100 \mu \mathrm{m}$, as shown in Fig. 3 .

Thermal stability of the alloys was investigated by DSC, and the DSC curves of the samples are shown in Fig. 4. All of the DSC traces exhibit exothermic reactions corresponding to crystallization of the undercooled liquid. However, glass transition temperatures of the alloys cannot be well defined. Only tentatively determined $T_{\mathrm{g}}$ values of the alloys are shown in Fig. 4. It is found that for all of the series, increasing the total amount of tungsten and boron contents results in the improvement in glass transition temperatures. Glass transition temperatures of the alloys are found to be between 1017 and $1130 \mathrm{~K}$. Similar to the glass transition temperatures, it is observed that for all of the series, crystallization temperatures of the alloys increase with the total amount of tungsten and boron contents. The first crystallization temperatures, $T_{\mathrm{x} 1}$, of the alloys are determined to be between 1060 and $1177 \mathrm{~K}$. In addition, DSC curves also show that crystallization of glass structure is a two-step process for all of the alloys studied.

Melting temperatures of the alloys were also determined and are listed in Table 1. It is found that melting temperatures of the alloys in the first series are around $1400 \mathrm{~K}$. The melting temperatures of the alloys in the second and third series are determined to be around $1600 \mathrm{~K}$. Liquidus temperatures of the alloys could not be measured because they are beyond the experimental limit, $1840 \mathrm{~K}$, of the

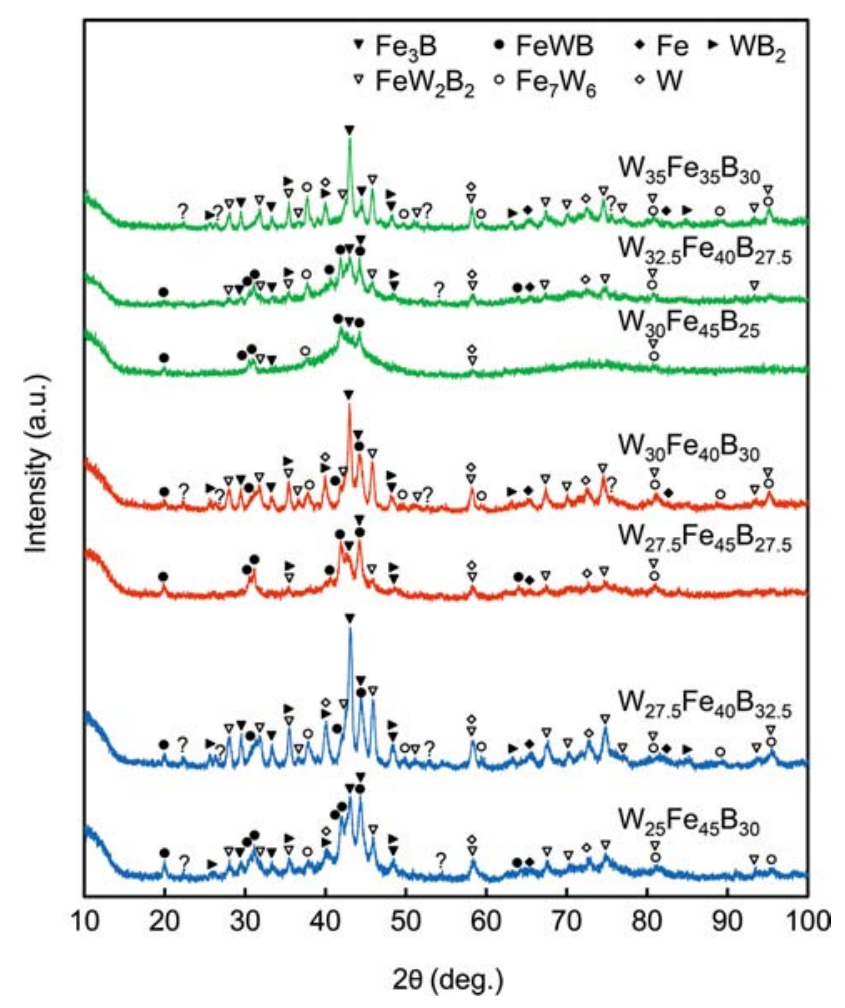

Fig. 3 XRD patterns of the $100-\mu \mathrm{m}$-thick samples of the alloys

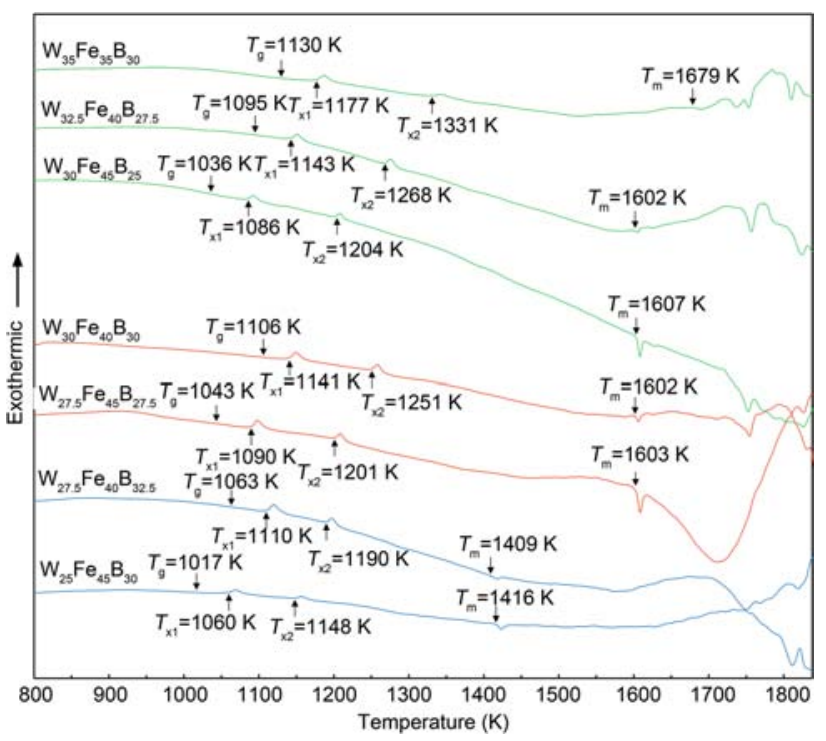

Fig. 4 DSC curves of the $20-\mu \mathrm{m}$-thick samples of the alloys

DSC instrument used. Also, visual examination of the samples after DSC experiments revealed that none of the samples completely melted. Thermal properties of the alloys are summarized in Table 1.

In addition, Vickers hardness values of the alloys are determined, and they are found to be between 1340 and $1634 \mathrm{HV}$ (Table 1). It is clearly seen that microhardnesses 
Table 1 Thermal properties $\left(T_{\mathrm{g}}, T_{\mathrm{x}}, T_{\mathrm{m}}\right)$ and Vickers hardness values of $\mathrm{W}-\mathrm{Fe}-\mathrm{B}$ alloys

\begin{tabular}{llllllll}
\hline Series & Alloy & $T_{\mathrm{g}}(\mathrm{K})$ & $T_{\mathrm{x} 1}(\mathrm{~K})$ & $T_{\mathrm{x} 2}(\mathrm{~K})$ & $T_{\mathrm{m}}(\mathrm{K})$ & $T_{\mathrm{L}}(\mathrm{K})$ & Hardness $(\mathrm{HV})$ \\
\hline 1 & $\mathrm{~W}_{25} \mathrm{Fe}_{45} \mathrm{~B}_{30}$ & 1017 & 1060 & 1148 & 1416 & - & 1340 \\
& $\mathrm{~W}_{27.5} \mathrm{Fe}_{40} \mathrm{~B}_{32.5}$ & 1063 & 1110 & 1190 & 1409 & - & 1545 \\
2 & $\mathrm{~W}_{27.5} \mathrm{Fe}_{45} \mathrm{~B}_{27.5}$ & 1043 & 1090 & 1201 & 1603 & - & 1356 \\
3 & $\mathrm{~W}_{30} \mathrm{Fe}_{40} \mathrm{~B}_{30}$ & 1106 & 1140 & 1251 & 1602 & - & 1608 \\
& $\mathrm{~W}_{30} \mathrm{Fe}_{45} \mathrm{~B}_{25}$ & 1036 & 1086 & 1204 & 1607 & 1485 \\
& $\mathrm{~W}_{32.5} \mathrm{Fe}_{40} \mathrm{~B}_{27.5}$ & 1095 & 1143 & 1268 & 1602 & - & 1644 \\
& $\mathrm{~W}_{35} \mathrm{Fe}_{35} \mathrm{~B}_{30}$ & 1130 & 1177 & 1331 & 1679 & - \\
\hline
\end{tabular}

of the alloys improve by increasing the total amount of tungsten and boron contents.

\section{Discussion}

Samples of the alloys with the thickness of $20 \mu \mathrm{m}$ are obtained as amorphous. However, in order to obtain fully amorphous structure, these alloys must not only be completely melted at high temperatures to dissolve all of the intermetallic compounds having high melting points, but also cooled down with high enough cooling rates to avoid crystallization. The production technique used in this study satisfied these requirements. Obviously, this technique is not a suitable approach to produce ribbons of metallic glasses for industrial applications. However, this technique is used only to guarantee that all of the alloys are obtained as amorphous regardless of their compositions so that their thermal and mechanical properties can be determined as a function of tungsten and boron contents.

For all of the series, it is clearly seen that increasing tungsten and boron contents increases glass transition and crystallization temperature (Fig. 5). This result is not surprising because alloys containing higher amount of tungsten and boron are expected to contain higher number of $\mathrm{W}-\mathrm{W}, \mathrm{B}-\mathrm{B}$ and $\mathrm{W}-\mathrm{B}$ bonds, whose cohesive energies are 860 [14], 563 [14] and $797 \mathrm{~kJ} / \mathrm{mol}$ [15], respectively. Because of this increase in total cohesive energy, the amorphous structure becomes more stable, which results in the improvement in glass transition and crystallization temperatures.

Moreover, for a constant iron content, increasing tungsten and decreasing boron contents improve crystallization temperatures (see Fig. 6). However, for alloys containing 45 at $\% \mathrm{Fe}$, increasing tungsten content higher than 27.5 at $\%$ does not result in any further increase in crystallization temperature. Similarly, for alloys containing 40 at $\% \mathrm{Fe}$, no additional improvement in crystallization temperature is observed after the tungsten content higher than 30 at\%. It is interesting to note that for both cases, no further improvements in crystallization temperatures are observed for alloys having higher tungsten content than boron content. For a constant iron content, it is very likely that when tungsten content is higher than boron content, the number of $\mathrm{W}-\mathrm{W}$ bonds is increased and the number of B-B and W-B bonds are decreased. For this reason, the increase in total cohesive energy because of the increase in the number of $\mathrm{W}-\mathrm{W}$ bonds is balanced by reduction in total cohesive energy because of the decrease in the number of B-B and W-B bonds and total cohesive energy stays almost constant. As a result, glass transition and crystallization temperatures remain unchanged. This result is very important for designing new W-Fe-B-based alloys, which have high crystallization temperature and optimum tungsten, iron and boron contents.

Glass transition and crystallization temperatures of $\mathrm{W}_{35} \mathrm{Fe}_{35} \mathrm{~B}_{30}$ alloy are the highest values reported for $\mathrm{W}-$ $\mathrm{Fe}-\mathrm{B}$ metallic glasses until now. Among the W-based metallic glasses, only crystallization temperatures of $\mathrm{W}_{45} \mathrm{Re}_{23} \mathrm{Ru}_{15} \mathrm{~B}_{17}$ [10] and $\mathrm{W}_{56} \mathrm{Ir}_{23} \mathrm{~B}_{21}$ [10] are higher than that of $\mathrm{W}_{35} \mathrm{Fe}_{35} \mathrm{~B}_{30}, 1177 \mathrm{~K}$. Also, crystallization temperature of this alloy is higher than or comparable with the most of those of the other refractory metal-based metallic glasses (see Table 2). Only crystallization temperatures of $(\mathrm{Ta}, \mathrm{W})_{80} \mathrm{Si}_{10} \mathrm{~B}_{10}$ [2], $\mathrm{Ta}_{55} \mathrm{Ir}_{45}$ [3], $(\mathrm{Nb}, \mathrm{Ta})_{55}(\mathrm{Rh}, \mathrm{Ir})_{45}$ [4] and $\mathrm{Re}_{49.7} \mathrm{~B}_{18.4} \mathrm{Zr}_{7.5} \mathrm{Si}_{17.4} \mathrm{Nb}_{7.0}$ [8] are significantly higher than the crystallization temperature of the alloy $\mathrm{W}_{35} \mathrm{Fe}_{35} \mathrm{~B}_{30}$ synthesized in this study.

In addition, since liquidus temperatures of the alloys cannot be measured by DSC analysis, the well-known GFA parameters such as $T_{\mathrm{g}} / T_{\mathrm{L}}$ and $T_{\mathrm{x}} /\left(T_{\mathrm{g}}+T_{\mathrm{L}}\right)$ cannot be determined. Therefore, it is not possible to compare the alloys in terms of their GFA parameters. However, effects of tungsten and boron contents on critical casting thickness of the alloys can still be discussed by comparing the XRD patterns of $100-\mu$ m-thick samples of the alloys (Fig. 3). It is clearly seen that for all series, increasing total amount of tungsten and boron contents decreases the amount of glass phase in the alloys, which indicates deterioration in GFA. This reduction in GFA is most likely due to the increase in liquidus temperature of the alloys, which results from its higher tungsten and boron contents. Although increasing 


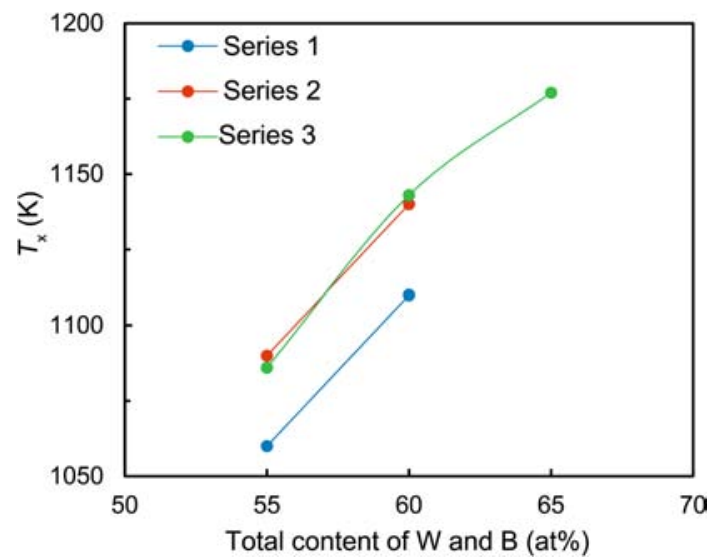

Fig. 5 Change in crystallization temperature as a function of total tungsten and boron content

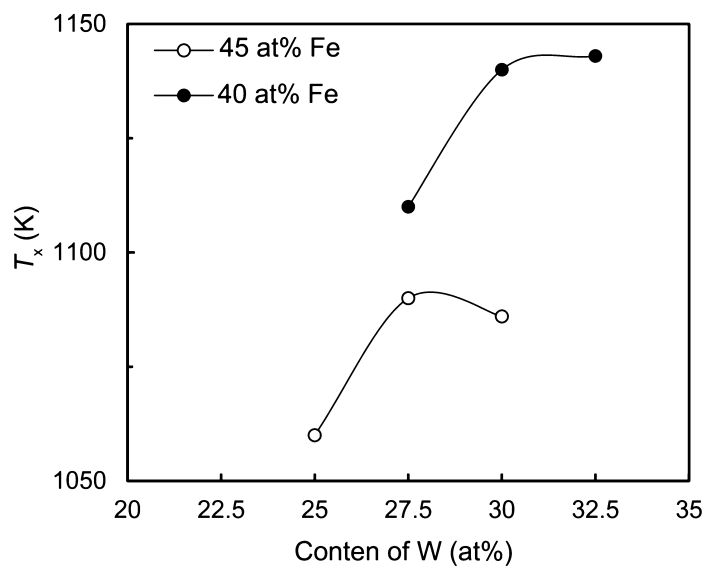

Fig. 6 Change of crystallization temperature as a function of tungsten content for constant iron contents of 40 and 45 at\%

tungsten and boron contents increases glass transition temperatures of the alloys, it also increases liquidus temperatures of the alloys. If increase in liquidus temperature is higher than that of glass transition temperature, minimum cooling rate required to obtain fully amorphous structure also increases. For this reason, critical casting thickness must be reduced to satisfy this cooling rate. In addition, XRD results of $100-\mu \mathrm{m}$-thick samples of alloys indicate that for constant iron contents, increasing tungsten and decreasing boron contents improve GFA of the alloys. Comparing XRD patterns of $100-\mu \mathrm{m}$-thick samples of alloys containing 45 at $\% \mathrm{Fe}, \mathrm{W}_{25} \mathrm{Fe}_{45} \mathrm{~B}_{30}, \mathrm{~W}_{27.5} \mathrm{Fe}_{45} \mathrm{~B}_{27.5}$ and $\mathrm{W}_{30} \mathrm{Fe}_{45} \mathrm{~B}_{25}$, clearly shows that the amount of glass phase increases with tungsten content. The same result is observed when XRD patterns of $100-\mu \mathrm{m}$-thick samples of alloys containing 40 at $\% \mathrm{Fe}, \mathrm{W}_{27.5} \mathrm{Fe}_{40} \mathrm{~B}_{32.5}, \mathrm{~W}_{30} \mathrm{Fe}_{40} \mathrm{~B}_{30}$ and $\mathrm{W}_{32.5} \mathrm{Fe}_{40} \mathrm{~B}_{27.5}$, are compared. It is already shown that for constant iron content, increasing tungsten and decreasing boron contents increase glass transition and
Table 2 Crystallization temperatures of several melt-spun refractory metal-based metallic glasses

\begin{tabular}{|c|c|c|c|}
\hline Alloy & $T_{\mathrm{x} 1}(\mathrm{~K})$ & $T_{\mathrm{x} 2}(\mathrm{~K})$ & Ref. \\
\hline$(\mathrm{Ta}, \mathrm{W})_{80} \mathrm{Si}_{10} \mathrm{~B}_{10}$ & $1310-1456$ & - & {$[2]$} \\
\hline$(\mathrm{Hf}, \mathrm{Ta})_{80} \mathrm{Si}_{10} \mathrm{~B}_{10}$ & $940-1220$ & - & {$[2]$} \\
\hline$(\mathrm{Ta}, \mathrm{Nb}, \mathrm{V})_{80} \mathrm{Si}_{10} \mathrm{~B}_{10}$ & $930-1210$ & - & {$[2]$} \\
\hline $\mathrm{Ta}_{55} \mathrm{Ir}_{45}$ & 1340 & - & {$[3]$} \\
\hline $\mathrm{Ta}_{55} \mathrm{Ni}_{45}$ & 990 & - & {$[3]$} \\
\hline$(\mathrm{Nb}, \mathrm{Mo})_{80} \mathrm{Si}_{10} \mathrm{~B}_{10}$ & $1020-1120$ & - & {$[2]$} \\
\hline$(\mathrm{Nb}, \mathrm{Ta})_{55}(\mathrm{Rh}, \mathrm{Ir})_{45}$ & $951-1338$ & - & {$[4]$} \\
\hline $\mathrm{Nb}_{70} \mathrm{~W}_{10} \mathrm{Si}_{20}$ & 1027 & - & {$[5]$} \\
\hline $\mathrm{Nb}_{70} \mathrm{Mo}_{10} \mathrm{Si}_{20}$ & 1008 & - & {$[5]$} \\
\hline$(\mathrm{Mo}, \mathrm{Cr}, \mathrm{Fe})_{80}(\mathrm{P}, \mathrm{B}, \mathrm{C}, \mathrm{Si})_{20}$ & $1104-1186$ & - & {$[6]$} \\
\hline $\mathrm{Mo}_{48} \mathrm{TM}_{32} \mathrm{P}_{12} \mathrm{~B}_{8}$ & $1078-1151$ & - & {$[6]$} \\
\hline$\left(\mathrm{Mo}_{0.6} \mathrm{Ru}_{0.4}\right)_{78-86} \mathrm{~B}_{22-14}$ & $1020-1090$ & - & [7] \\
\hline $\mathrm{Re}_{49.7} \mathrm{~B}_{18.4} \mathrm{Zr}_{7.5} \mathrm{Si}_{17.4} \mathrm{Nb}_{7.0}$ & 1331 & 1347 & {$[8]$} \\
\hline $\mathrm{Re}_{46.4} \mathrm{~B}_{33.4} \mathrm{Hf}_{4} \mathrm{Si}_{16.2}$ & 1128 & 1139 & {$[8]$} \\
\hline $\mathrm{W}_{70} \mathrm{Si}_{20} \mathrm{~B}_{10}$ & 1033 & - & [9] \\
\hline $\mathrm{W}_{45} \mathrm{Re}_{23} \mathrm{Ru}_{15} \mathrm{~B}_{17}$ & 1273 & - & {$[10]$} \\
\hline $\mathrm{W}_{56} \mathrm{Ir}_{23} \mathrm{~B}_{21}$ & 1271 & 1305 & {$[10]$} \\
\hline $\mathrm{W}_{46} \mathrm{Ru}_{37} \mathrm{~B}_{17}$ & 1174 & 1208 & {$[10]$} \\
\hline $\mathrm{W}_{46} \mathrm{Ru}_{37} \mathrm{~B}_{12} \mathrm{Si}_{5}$ & 1172 & 1202 & {$[10]$} \\
\hline $\mathrm{W}_{46} \mathrm{Ru}_{37} \mathrm{~B}_{15} \mathrm{Si}_{2}$ & 1167 & 1201 & {$[10]$} \\
\hline $\mathrm{W}_{38} \mathrm{Ir}_{17} \mathrm{Ru}_{31} \mathrm{~B}_{14}$ & 1119 & 1232 & {$[10]$} \\
\hline $\mathrm{W}_{54} \mathrm{Rh}_{26} \mathrm{~B}_{20}$ & 1064 & 1152 & {$[10]$} \\
\hline $\mathrm{W}_{37} \mathrm{Ru}_{31} \mathrm{Rh}_{18} \mathrm{~B}_{14}$ & 1049 & - & {$[10]$} \\
\hline $\mathrm{W}_{30} \mathrm{Fe}_{38} \mathrm{~B}_{25} \mathrm{C}_{7}$ & 1067 & 1128 & {$[11]$} \\
\hline $\mathrm{W}_{33} \mathrm{Ni}_{32} \mathrm{~B}_{35}^{\mathrm{a}}$ & 1146 & - & [12] \\
\hline
\end{tabular}

${ }^{a}$ Prepared by sputtering

crystallization temperatures. Since GFA also improves with increasing tungsten and decreasing boron contents, liquidus temperatures must either remain constant or decrease with increasing tungsten and decreasing boron contents so that minimum cooling rate required to obtain fully amorphous structure decreases. In addition, increasing tungsten and decreasing boron contents may also hinder precipitation of the borides during solidification; as a result, minimum cooling rate decreases further. However, this minimum cooling rate is still higher than the cooling rate of $100-\mu \mathrm{m}$ - thick samples, so none of the $100-\mu \mathrm{m}$-thick samples have fully amorphous structure. Besides, it is not possible to determine exactly which of these mechanisms are more important than the other one since we cannot measure the liquidus temperatures of the alloys.

Similar to the results of crystallization temperatures, alloys containing higher amount of tungsten and boron have the higher microhardness values than the others. The reason for these alloys to have higher microhardness values is that they have higher number of $\mathrm{W}-\mathrm{W}$ and $\mathrm{W}-\mathrm{B}$ bonds than the others. Microhardness of the $\mathrm{W}_{35} \mathrm{Fe}_{35} \mathrm{~B}_{30}$ alloy is 
Table 3 Vickers hardness values of several melt-spun refractory metal-based metallic glasses

\begin{tabular}{lll}
\hline Alloy & Hardness (HV) & Ref. \\
\hline $\mathrm{W}_{33} \mathrm{Ni}_{32} \mathrm{~B}_{35}^{\mathrm{a}}$ & 2447 & {$[12]$} \\
$\left(\mathrm{W}_{0.6} \mathrm{Re}_{0.4}\right)_{0.76} \mathrm{~B}_{24}^{\mathrm{a}}$ & 2400 & {$[13]$} \\
$\mathrm{Mo}-\mathrm{Fe}-\mathrm{B}$ & $1784-1988$ & {$[6]$} \\
$\mathrm{Mo}-\mathrm{Co}-\mathrm{B}$ & $1682-1733$ & {$[6]$} \\
$\mathrm{Mo}-\mathrm{Co}-\mathrm{Fe}-\mathrm{B}$ & $1784-1815$ & {$[6]$} \\
$\mathrm{Re}_{49.7} \mathrm{~B}_{18.4} \mathrm{Zr}_{7.5} \mathrm{Si}_{17.4} \mathrm{Nb}_{7.0}$ & 1784 & {$[8]$} \\
$\mathrm{Re}_{46.4} \mathrm{~B}_{33.4} \mathrm{Hf}_{4} \mathrm{Si}_{16.2}$ & 1377 & {$[8]$} \\
$\mathrm{Mo}_{70} \mathrm{Si}_{20} \mathrm{~B}_{10}$ & 1020 & {$[9]$} \\
$\mathrm{W}_{70} \mathrm{Si}_{20} \mathrm{~B}_{10}$ & 1326 & {$[9]$} \\
$\mathrm{W}_{45} \mathrm{Re}_{23} \mathrm{Ru}_{15} \mathrm{~B}_{17}$ & 1764 & {$[10]$} \\
$\mathrm{W}_{46} \mathrm{Ru}_{37} \mathrm{~B}_{17}$ & 1713 & {$[10]$} \\
$\mathrm{W}_{45} \mathrm{Ru}_{36} \mathrm{~B}_{17} \mathrm{Hf}_{2}$ & 1682 & {$[10]$} \\
$\mathrm{W}_{46} \mathrm{Ru}_{37} \mathrm{~B}_{15} \mathrm{Si}_{2}$ & 1468 & {$[10]$} \\
$\mathrm{W}_{46} \mathrm{Ru}_{37} \mathrm{~B}_{12} \mathrm{Si}_{5}$ & 1346 & {$[10]$} \\
$\mathrm{W}_{30} \mathrm{Fe}_{38} \mathrm{~B}_{25} \mathrm{C}_{7}$ & 1219 & {$[11]$} \\
\hline
\end{tabular}

${ }^{a}$ Prepared by sputtering

found to be around $1634 \mathrm{HV}$, which is the highest microhardness value reported for $\mathrm{W}-\mathrm{Fe}-\mathrm{B}$ metallic glasses until now and higher than microhardnesses of some of W-based metallic glasses. Also, this hardness value is higher than or comparable with microhardnesses of the others (see Table 3). Only microhardness of $\mathrm{W}_{33} \mathrm{Ni}_{32} \mathrm{~B}_{35}$ [12], $\left(\mathrm{W}_{0.6} \mathrm{Re}_{0.4}\right)_{0.76} \mathrm{~B}_{24}$ [13] and Mo-Fe-B [6] is considerably higher than the microhardness of alloy $\mathrm{W}_{35} \mathrm{Fe}_{35} \mathrm{~B}_{30}$ synthesized in this study.

Although critical casting thicknesses of the alloys investigated in this study are quite low, as the others, there are still some potential applications where high thermal stability and hardness are required. For example, amorphous powders of the alloys having diameter smaller than 20-30 $\mu \mathrm{m}$ can be used as coating material with arc plasma spraying. Also, the same amorphous powders can be sintered by spark plasma sintering technique to manufacture pieces having larger dimensions. Finally, amorphous powders of the alloys can be used as reinforcement of metal matrix composites.

\section{Conclusions}

$\mathrm{W}-\mathrm{Fe}-\mathrm{B}$ metallic glasses containing various amounts of tungsten, iron and boron were synthesized by piston and anvil method in an arc furnace. The results are summarized as follows:

(1) First crystallization temperature of the alloys was found to be between 1060 and $1177 \mathrm{~K}$.
(2) Increasing tungsten and boron contents improves the glass transition and crystallization temperatures significantly, but deteriorates GFA of the alloys.

(3) For a constant iron content, increasing the tungsten content to the level higher than boron content does not result in any further increase in both glass transition and crystallization temperatures.

(4) For a constant iron content, increasing tungsten content and decreasing boron content improve GFA of the alloys.

(5) Glass transition, $1106 \mathrm{~K}$, and crystallization temperatures, $1177 \mathrm{~K}$, of $\mathrm{W}_{35} \mathrm{Fe}_{35} \mathrm{~B}_{30}$ alloy are the highest values reported for $\mathrm{W}-\mathrm{Fe}-\mathrm{B}$ metallic glasses until now.

(6) Microhardness value obtained for alloy $\mathrm{W}_{35} \mathrm{Fe}_{35} \mathrm{~B}_{30}$, $1634 \mathrm{HV}$, is the highest microhardness value reported for W-Fe-B metallic glasses so far. This microhardness value is also higher than microhardnesses of some of the $\mathrm{W}$-based metallic glasses.

Acknowledgments This study was supported by the Research Council of Afyon Kocatepe University (Grant No. 12.FEN.BİL.37).

\section{References}

[1] A. Inoue, A. Takeuchi, Acta Mater. 59, 2243 (2011)

[2] T. Yoshitake, Y. Kubo, H. Igarashi, Mater. Sci. Eng. 97, 269 (1988)

[3] L. Rohr, P. Reimann, T. Richmond, H.J. Güntherodt, Mater. Sci. Eng., A 133, 715 (1991)

[4] C.C. Koch, D.M. Kroeger, J.O. Scarbrough, B.C. Giessen, Phys. Rev. B 22, 5213 (1980)

[5] T. Masumoto, A. Inoue, S. Sakai, H. Kimura, A. Hoshi, Trans. JIM 21, 115 (1980)

[6] M.K. Mahan, B.L. Jha, J. Mater. Sci. Lett. 15, 1594 (1980)

[7] M. Mehra, R. Schultz, W.L. Johnson, J. Non-Cryst. Solids 61-62, 859 (1984)

[8] R. Yoshimoto, Y. Nogi, R. Tamura, S. Takeuchi, Mater. Sci. Eng., A 449-451, 260 (2007)

[9] A. Inoue, S. Sakai, H. Kimura, K. Masumoto, A. Hoshi, Scr. Mater. 14, 235 (1980)

[10] M. Ohtsuki, K. Nagata, R. Tamura, S. Takeuchi, Mater. Trans., JIM 46, 48 (2005)

[11] Z.Y. Suo, Y.L. Song, B. Yu, K.Q. Qiu, Mater. Sci. Eng., A 528, $2912(2011)$

[12] S.V. Madge, A. Caron, R. Gralla, G. Wilde, S.K. Mishra, Intermetallics 47, 6 (2014)

[13] A.P. Thakoor, J.L. Lamb, S.K. Khanna, M. Mehra, W.L. Johnson, J. Appl. Phys. 58, 3409 (1985)

[14] V.V. Brazhkin, A.G. Lyapin, R.J. Hemley, Philos. Mag. A 82, 231 (2002)

[15] C.J. Qi, Y.H. Jiang, Y.Z. Liu, R. Zhou, Ceram. Int. 40, 5843 (2014) 